\title{
Criteria for loading slabs during construction
}

\section{A. W. Beeby}

\section{A. E. K. Jones, Arup Research \& Development}

The author puts forward a robust technical argument for changing the criteria for loading slabs during construction and backs this up with actual data from Cardington. I would like to raise three points, one related to the interpretation of the data, and two further points related to the practical implications of such a change.

The early sections of the paper develop the concept of a factor $\boldsymbol{F}_{\text {cr }}$ which, for the immature concrete (cube strength $f_{\mathrm{c}}$ ), limits the load carried $(\boldsymbol{w})$ to that which would cause a similar amount of cracking to the full service load $\left(\boldsymbol{w}_{\text {ser }}\right)$ being applied to the mature concrete (strength $f_{\mathrm{cu}}$ ). It is argued that provided this load is not exceeded during construction, the performance of the slab under full service load in later life will be acceptable.

$$
\left(\frac{\boldsymbol{w}}{\boldsymbol{w}_{\mathrm{ser}}}\right)\left(\frac{\boldsymbol{f}_{\mathrm{cu}}}{\boldsymbol{f}_{\mathrm{c}}}\right)^{0.6}=\boldsymbol{F}_{\mathrm{cr}} \leqslant 1
$$

Reviewing the results from Cardington (Figs 3 and 4 and Table 3), the author shows that the long-term deflections of the slabs, under virtually the full design serviceability load, are dependent on the maximum $\boldsymbol{F}_{\mathrm{cr}}$ achieved during construction even when this factor was below the recommended value of $1 \cdot 0$. The theory developed would suggest that once the slabs reached an $\boldsymbol{F}_{\mathrm{cr}}$ of 1.0 under service loads then the deflection of all slabs, with a maximum $\boldsymbol{F}_{\mathrm{cr}}$ during construction of less than 1 , should be equal. This discrepancy may be explained by the fact that $\boldsymbol{F}_{\text {cr }}$ calculated under the current loading is still significantly less than 1.0 due to the higher-than-characteristic concrete strength, but the author's interpretation of this would be appreciated.

What these graphs do show is that the deflections of real slabs, under real loads, are sensitive to the construction process. To emphasise this point the following figure gives the deflection for locations 3 and 6 which occurred between 260 and 500 days. It can be seen that the increase in deflection occurring over a year from the time of construction is dependent on the $\boldsymbol{F}_{\text {cr }}$ (or amount of cracking) caused during construction.

What this means practically is that any change in construction, which introduces a greater degree of cracking at early age, will

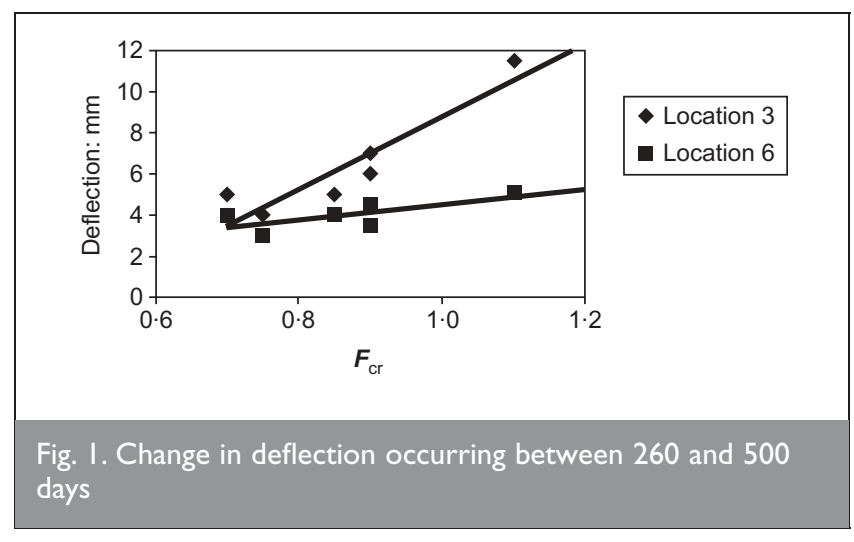

increase deflection during the life of the building at least for loads below the full serviceability load. It is well-established that most buildings and particularly commercial office developments ${ }^{8}$ see only a very small part of their service design load and are therefore working in this constructioninfluenced zone.

Much of the trades that follow on from the structural frame are experience-based; that is to say that they do not know what the design code limit to deflection should be but they know that the last time they worked on a concrete building the details they used worked. This is often a problem on long-span buildings where the structural engineer has to go to some effort to describe how the building may deflect. What is proposed by this paper would lead to less stiff slabs with greater ranges of deflection during typical loading and unloading cycles. This needs to be considered in the whole rather than for just the concrete frame.

The test results shown indicate that the critical case for $\boldsymbol{F}_{\mathrm{cr}}$ for the Cardington building was generally the casting of the slab above. At this time the concrete properties are likely to be approaching their characteristic values. Under different propping arrangements or different spans it is possible that the stripping of the soffit formwork will cause the critical $\boldsymbol{F}_{\mathrm{cr}}$ and the concrete properties will be significantly less than their 28-day value.

At the stripping-of-formwork stage the only construction load on the slab is the dead load. The application of equation (4) in the paper ensures that the deflection and cracking under the construction load considered is no greater than that of the slab 
with mature concrete properties under full design serviceability loads. However, as this deflection and cracking is effectively locked in by the dead weight of the slab, any further load (i.e. any imposed load) will cause the overall deflection (and cracking) to exceed this limit. Large locked-in self-weight deflections and cracks may not be an issue but these will need to be added to the construction tolerances for the ensuing trades. If the soffit is visible or has a restricted service zone these locked-in deflections may be unacceptable.

In addition, it is concluded that the time of loading may not be very significant for the long-term creep. This may be true for transient loads such as those from propping but would seem unlikely to be true for permanent loads such as those caused by the dead load. Indeed, both BS 8110 Part $2^{7}$ and Model Code $90^{10}$ make specific allowance in the calculation of the creep coefficient for the time of loading. This will again increase the self-weight contribution to the final deflection.

In conclusion, while the theory of the approach proposed in the paper appears sound, the practical implications in comparison with current practice will be

(a) larger dead-load deflections and associated cracking

(b) larger deflection ranges under normal working loads

(c) larger long-term deflections and associated cracking.

While these outcomes may be acceptable for particular projects, the implications to the building as a whole should be considered before changing proven construction practice. It is suggested that for many buildings it may be appropriate to take a lower value of $\boldsymbol{w}_{\text {ser }}$ than the full service design load. The author's comments on this would be welcome.

\section{Author's reply}

Dr Tony Jones is thanked for his interest in the paper and thoughtful comments.

I remain somewhat unsure of the full import of Dr Jones' first point and therefore am uncertain whether I am answering his point fully and can only try to restate, possibly rather more fully, what $\boldsymbol{F}_{\mathrm{cr}}$ intends to do. The concept was that, provided $\boldsymbol{F}_{\mathrm{cr}}$ did not exceed 1.0 during construction, then the deflection or cracking in service would not be greater than that implicit in the design. It must be noted that we do not know what deflection is implicit in the design. The designer may calculate the deflection under the required conditions set out in the code but this is not the same thing. As Dr Jones effectively implies, our design procedures are 'calibrated' by experience so that we are reasonably confident that they will result in satisfactory designs. There are many implicit factors and assumptions in these methods which have never been quantified. For example, we know that time of loading has an effect on deflections; what assumptions are included within current design methods for the time of application of the dead load and the live load? What construction sequence is assumed? What propping, repropping and backpropping strategy is assumed in the design? What climatic regime is assumed? A structure constructed predominantly in the summer could behave significantly differently to one constructed predominantly during the winter. All these things affect the service performance to some extent but we do not consider them explicitly, although implicitly, assumptions on these must be covered by the 'experience' element of the design rules. The proposition made in the paper, although based on the factors which will influence the simple calculation of deflections, should be interpreted as saying no more than that these implicit assumptions should not be seriously violated by the construction process provided that $\boldsymbol{F}_{\mathrm{cr}}$ and $\boldsymbol{F}_{\mathrm{W}}$ do not exceed 1 during construction. It may be true that, if the slab is loaded to a value of $\boldsymbol{F}_{\mathrm{cr}}$ below 1 during construction then the final deflection may be lower even where the slab is loaded to $\boldsymbol{F}_{\mathrm{cr}}=1$ in service.

Hossain and Vollum at Imperial College ${ }^{11}$ have studied the deflection behaviour of the Cardington structure in great detail and have carried out calculations to show the effect of different assumed construction loadings and different striking times for the formwork. This work suggests that ignoring the construction loading does indeed result in lower calculated final deflections. This, however, corresponds to a very gross reduction in $\boldsymbol{F}_{\mathrm{cr}}$ during construction.

A second point in Dr Jones' contribution relates to creep and age at loading. It is well-known, as stated in the contribution, that creep is higher when the load is applied earlier. The question is: how significant is this effect? Hossain and Vollum ${ }^{11}$ show that there is indeed an increase in deflection where the formwork is struck earlier. The difference between the calculated deflection at 800 days of slabs struck at one to three days compared with slabs struck at seven days appears to average about $1 \mathrm{~mm}$. This corresponds to about 5\% of the total deflection. Since it is probably unreasonable to assume that the deflection can be assessed to any great accuracy, it can reasonably be argued that, while the effect of time of loading exists, it is not practically significant compared with other uncertainties. This confirms the results of a brief parameter study mentioned in the paper and the conclusions of Harrison. ${ }^{3}$

I can understand Dr Jones' idea of suggesting the use of a lower value for $\boldsymbol{W}_{\text {ser }}$ since it is true that $\boldsymbol{W}_{\text {ser }}$ is rarely, if ever, actually applied to a structure. Nevertheless, this is a point where the assumption made in the design is clear; the deflection is calculated under the full service load and my inclination is therefore to stick with this. In other codes, lower values are used and it could well then be appropriate to take whatever value is specified for checking the serviceability limits in the code being used. Some degree of safety may well need to be built into the equations but my inclination would be to apply this to the concrete strength $\left(f_{\mathrm{c}}\right)$ rather than to the loading. This is suggested in the paper, although values are not proposed.

Since Dr Jones has raised concerns regarding the possibility that striking times might be significantly reduced using the proposals in the paper, one final point may be made. The paper covers only part of the work carried out on striking and propping loads in relation to the Cardington structure. The second part is reported in a later paper in Structures and Buildings. ${ }^{12}$ This shows that it is likely that current methods of calculating the loading on slabs due to the construction process significantly underestimate the actual loading on the slab immediately below a slab being cast. Thus, while application of the $\boldsymbol{F}_{\mathrm{cr}}$ rule may suggest striking can take place at lower concrete strengths, this will be counteracted to a considerable 
degree by the use of significantly higher, and more realistic, construction loads than in the past at a slightly later stage in the construction.

\section{REFERENCES}

8. AUSTIN J. A. Over design: fact or fiction. The Structural Engineer, 1998, 76, No. 2, 20 January.

9. BRITISH STANDARDS InStitution. Structural Use of Concrete. Part 2: Code of Practice for Special Circumstances. BSI, London, 1985, BS 8110: 1985: Part 2.
10. CEB-FIP. Model Code 1990. Thomas Telford, London, 1993.

11. Hossain T. R. and Vollum R. L. Prediction of slab deflections and validation against Cardington data. Proceedings of the Institution of Civil Engineers Structures and Buildings, 2002, 152, 235-248.

12. BeEBY A. W. The forces in backprops during constructing of flat slab structures. Proceedings of the Institution of Civil Engineers Structures and Buildings, 2001, 146, No. 3, August, 307-317. 